\title{
ATRIBUIBILIDAD AL ESTADO DE CHILE DE ACTOS Y OMISIONES DE SUS EMPRESAS PÚBLICAS DEL SECTOR EXTRACTIVO A LA LUZ DE LA JURISPRUDENCIA DE TRIBUNALES REGIONALES DE DERECHOS HUMANOS
}

\author{
ATTRIBUTABILITY TO THE CHILEAN STATE OF ACTS AND \\ OMISSIONS OF ITS STATE-OWNED ENTERPRISES OF THE \\ EXTRACTIVE SECTOR IN THE LIGHT OF THE CASE-LAW OF \\ REGIONAL HUMAN RIGHTS COURTS
}

\author{
JUDITH SCHÖNSTEINER* \\ Vicente Martínez ${ }^{* *}$ \\ CARLOS MiRANDA $^{* * *}$
}

\begin{abstract}
RESUMEN: Este artículo mostrará cómo las dos grandes empresas públicas chilenas que están activas en el rubro extractivo, CODELCO y ENAP, pueden generar responsabilidad internacional del Estado por hechos internacionalmente ilícitos, particularmente, en materia ambiental o de derechos humanos. Para ello, se derivan criterios sobre atribuibilidad de actos y omisiones de CODELCO y ENAP al Estado, a partir del derecho internacional general y la jurisprudencia de tribunales de derechos humanos; estos criterios se aplican a la normativa y práctica administrativa de nuestro país para finalmente concluir que actos y omisiones de las empresas estudiadas efectivamente, son atribuibles al Estado de Chile.
\end{abstract}

Palabras clave: responsabilidad internacional del Estado; atribuibilidad; empresas de propiedad del Estado; empresas públicas; derechos humanos.

ABSTRACT: This article shows how the two large Chilean state-owned enterprises of the extractive sector, ENAP and CODELCO, may cause international state responsibility for internationally wrongful acts, for example, in human rights or environmental matters. To do so, we revise general international law and case-law from human rights courts to derive criteria of attribution of acts and omissions of state-owned enterprises to the State. Finally, we apply these criteria to the administrative legislation and practice regarding state-owned enterprises,

\footnotetext{
Doctora en derecho por la Universidad de Essex, Reino Unido, profesora asociada de la Facultad de Derecho e investigadora del Centro de Derechos Humanos de la Universidad Diego Portales. Dirección postal: República 112, Santiago. Código ORCID 0000-0002-8744-4258 Dirección electrónica: judith.schonsteiner@udp.cl. Esta investigación fue posible gracias al apoyo de ANID/Conicyt, Fondecyt de Iniciación No 11150853, "Responsabilidad internacional del Estado por acciones y omisiones de empresas estatales en materia de derechos humanos". Agradecemos comentarios de los y las asistentes de las XIV Jornadas de Derecho Administrativo en Punta Arenas (2017) y de los pares evaluadores, y el apoyo valioso de Marco Silva Soto, abogado.

** Abogado, Magíster en Derecho Público y Litigación Constitucional por la Universidad Diego Portales. Dirección postal Padre Restrepo 2636, Providencia. Código ORCID 0000-0003-1136-0979. Dirección electrónica: vicente.martinez@mail.udp.cl.

*** Abogado, Máster en Derecho por la Universidad de Wisconsin-Madison. Dirección postal: Avenida Andrés Bello 2711, piso 24, Las Condes. Código ORCID 0000-0002-0020-0702 Dirección electrónica:: carlos.miranda@mail.udp.cl.
} 
to conclude that the acts and omissions of the enterprises studied in this article are actually attributable to the State of Chile.

Keywords: international state responsibility; attribution; state-owned enterprises; human rights.

\section{INTRODUCCIÓN}

Las empresas de propiedad del Estado ("EPE") tienen un involucramiento importante en la explotación de recursos naturales en muchos países, por su rol estratégico, y Chile no es una excepción. Al mismo tiempo, las industrias extractivas suelen tener un alto impacto ambiental, social y de derechos humanos, tal como podemos ver, por ejemplo, en la bahía Quintero-Puchuncaví1. El Instituto Nacional de Derechos Humanos ("INDH") identifica 33 conflictos socio-ambientales relacionados con la minería ${ }^{2} .4$ de estos conflictos están relacionados con proyectos de CODELCO y ENAP33.

En el derecho internacional de los derechos humanos, los Estados tienen tres obligaciones: respetar (abstenerse de violar los derechos) ${ }^{4}$, proteger (propender a que terceros no violen derechos) ${ }^{5}$ y garantizar (tomar medidas para asegurar el pleno ejercicio de los derechos) ${ }^{6}$. Siendo claro que se podría demandar al Estado de Chile por falta de protección y garantía en relación con la actividad de las EPE, la pregunta que ha ido surgiendo con cada vez mayor fuerza en el debate internacional es si se podría demandar al Estado directamente por las acciones y omisiones de sus EPE, y cuáles serían los requisitos para ello. En relación con las EPE, surge así la pregunta de si tienen obligaciones de respetar los derechos humanos en el mismo sentido y con el mismo alcance que los órganos del Estado 7 . Mientras el análisis sustantivo de las obligaciones internacionales queda para otra investigación ${ }^{8}$, este artículo busca analizar solamente si son las acciones u omisiones de CODELCO y ENAP -incluyendo en materias ambientales y de derechos humanos- atribuibles al Estado de Chile.

En base a un test derivado del Proyecto de Artículos sobre Responsabilidad Internacional del Estado por Hechos Ilícitos ("Proyecto"), en las interpretaciones diferentes que le han dado los tribunales arbitrales, el Sistema Interamericano de Derechos Humanos ("SIA") y, en analogía, el Tribunal Europeo de Derechos Humanos ("TEDH”), el análisis pormenorizado de la normativa y práctica administrativa chilena mostrará que las dos grandes EPE chilenas que están activas en el rubro extractivo, CODELCO y ENAP, podrían generar esta responsabilidad. Esto se debe principalmente a que decisiones estratégicas y

\footnotetext{
1 Instituto Nacional de Derechos Humanos (2018); Hervé y Schönsteiner (2012).

2 Véase Instituto Nacional de Derechos Humanos (2018).

3 Instituto Nacional de Derechos Humanos (2018).

4 Medina (2018) p. 73.

5 Medina (2018) p. 79.

6 Medina (2018) p. 74

7 Véase, por ejemplo, BaCKer (2017).

${ }^{8}$ Artículos $1^{\circ}$ al $3^{\circ}$ del Proyecto de Artículos sobre Responsabilidad del Estado por hechos internacionalmente ilícitos, con Comentarios, 2001, A/56/10.
} 
presupuestarias importantes están directamente controladas por el ejecutivo, y a la aplicación de derecho público o especial a estas empresas. Si bien el SIA, que tiene jurisdicción sobre Chile, pareciera inclinarse por la atribuibilidad a causa del mero rol de propietario del Estado, mostraremos que incluso bajo la teoría más estricta del derecho general internacional', replicada por el TEDH, los actos y omisiones de CODELCO y ENAP son atribuibles directamente al Estado de Chile. En este sentido, la antigua teoría de los "actos de administración" (actos iure gestionis) debe ser, por lo menos, replanteada.

Ciertamente, la gobernanza de las EPE debiera ser lo más parecido posible a las empresas privadas ${ }^{10}$, para competir en igualdad de condiciones. Sin embargo, por lo menos en Chile, su estructura responde a una lógica de derecho público, y eso significa, como demostrará este artículo, que es el mismo Estado el que tiene que asumir, directamente, la responsabilidad por actos u omisiones contrarias al derecho internacional, incluyendo las que se impliquen violaciones de derechos humanos y ambientales.

La diferencia es relevante primero, porque el Estado tendrá que responder por daños en materia de derechos humanos, eventualmente más allá del patrimonio de un proyecto. $\mathrm{Y}$ segundo, porque las obligaciones del Estado de respetar, en virtud de la responsabilidad internacional directa, son de resultado, mientras que las obligaciones en relación con empresas privadas siempre son de medios, en virtud del estándar de debida diligencia en el deber de proteger $^{11}$. Así, el umbral para evidenciar la responsabilidad por no respetar los derechos humanos será menos exigente en los casos en los que proceda la atribución directa. Estas diferencias se extienden también a la debatida responsabilidad por actividades extraterritoriales de estas empresas ${ }^{12}$. Es por estas diferencias que el análisis desarrollado aquí no solamente es de interés dogmático o teórico, sino eminentemente práctico.

Para demostrar la posibilidad de que CODELCO y ENAP hagan incurrir al Estado de Chile directamente en responsabilidad internacional, se procederá en dos pasos: primero, se presenta los criterios de un test sobre atribuibilidad derivado de la costumbre, doctrina y jurisprudencia internacionales. Segundo, se revisará en qué medida se cumplen los presupuestos de atribuibilidad para CODELCO y ENAP.

\section{LOS CRITERIOS DEL DERECHO INTERNACIONAL SOBRE ATRIBUIBILIDAD}

Encontramos una tendencia en el derecho internacional económico de tratar a las EPE como empresas privadas. Por ejemplo, los árbitros bajo ICSID suelen otorgar ius standi a las EPE extranjeras ${ }^{13}$. Los fallos de distintos foros en los últimos años han reconocido responsabilidad del Estado por hechos de las EPE en el derecho internacional bajo ciertas

\footnotetext{
9 VANneste (2010) pp. 504-534.

10 OCDE (2015).

11 Pisillo Mazzeschi (2008) p. 491.

12 Véase, principalmente, Comité DESC, Observación General No 24. Debemos dejar un análisis detallado de tales obligaciones para otra oportunidad. Véase también Cuervo-Vazurra (2018).

13 Barnes (2019), crítica. Véase también BlyschaK (2011) y Feldman (2016).
} 
hipótesis ${ }^{14}$. En cuanto a la materia que nos ocupa en este análisis, la Corte Interamericana de Derechos Humanos ("Corte IDH”) comenzó a explicitar una teoría sobre la responsabilidad por acciones y omisiones de EPE en 2019, al igual que la Comisión Interamericana de Derechos Humanos ("CIDH”), mientras que el (TEDH) ha definido detallados criterios de atribuibilidad en varias décadas de jurisprudencia sobre cuestiones, principalmente, jurisdiccionales. Esta jurisprudencia es de especial interés, porque nos permitirá definir un modelo de atribuibilidad de responsabilidad por posibles violaciones de derechos humanos y ambientales por parte de las EPE.

a. Derecho internacional general, Corte International de Justicia y ARBITRAJE ECONÓMICO

El derecho internacional general sobre responsabilidad internacional del Estado está codificado en el Proyecto, adoptado en 2001 por la Comisión de Derecho Internacional. Si bien el Proyecto mismo no menciona directamente a las EPE, el comentario a su artículo 5o explica que puede haber atribuibilidad en caso de "entidades paraestatales, que ejercen atribuciones del poder público en lugar de los órganos del Estado, y en caso de antiguas empresas estatales que han sido privatizadas, pero conservan ciertas funciones públicas o normativas" ${ }^{15}$. El solo hecho de crear una EPE no hace atribuible su comportamiento posterior ${ }^{16}$. Sin embargo, se ha argumentado que un mecanismo de control establecido en el momento de la creación sí podría justificar la atribución de acciones u omisiones de la EPE al Estado ${ }^{17}$.

En la doctrina se ha considerado que los planteamientos del Proyecto no son del todo consistentes ${ }^{18}$. Más bien, se ha propuesto en base a la jurisprudencia arbitral y de la Corte Internacional de Justicia $-y$ creemos que correctamente ${ }^{19}$ - que la atribución debe realizarse en base al artículo 8 del Proyecto, cuando el ejercicio de funciones gubernamentales o públicas es fáctico $-\mathrm{y}$ no a través del artículo 5 como sugiere, vagamente, el Proyecto $^{20}$. En ambos casos, se podrán atribuir no solo acciones sino también omisiones de una $\mathrm{EPE}$ al Estado ${ }^{21}$. También hay quienes sostienen la posibilidad de atribución según artículo 4 del Proyecto bajo ciertas hipótesis relacionadas con la densidad de control que el Estado, particularmente el poder ejecutivo, ejercen sobre las $\mathrm{EPE}^{22}$. El silencio del comentario sobre el artículo 4 del Proyecto no es del todo convincente en este sentido ${ }^{23}$.

\footnotetext{
14 Véase, por ejemplo, Lee (2019), Ma (2019), Lee (2015), Petrochilos (2015) y Feit (2010). No siempre han sido consistentes, véase BADIA (2014), CORTESI (2017), BARNES (2019).

15 Proyecto, Comentario, A/56/10 (2001), párr. 2, p. 43. No profundizaremos sobre empresas estatales hoy privatizadas ya que no es la situación de las dos empresas que analizamos.

16 Proyecto, Comentario al artículo 8, párr. 6.

17 SCHÖNSTEINER (2019).

18 Véase, entre otros, DeReje (2016) p. 435.

19 SChÖnSteiner (2019), y Dereje (2016) p. 436.

20 Proyecto, Comentario al artículo 8, párr. 6.

21 Dereje (2016) pp. 421-424, y Proyecto comentario al artículo 8.

22 De Stefano (2020) p. 166.

23 Dereje (2016) p. 401, y Lee (2015) p. 130. Véase también Ding (2014). No consideramos necesario profundizar en el punto, ya que esta hipótesis claramente no es aplicable en los casos que aquí se analizan.
} 
La jurisprudencia arbitral en distintos foros, comenta De Stefano, ha usado los criterios de "nombramiento gubernamental (...) de la gerencia de la empresa; ordenes, directivas, recomendaciones o instrucciones por parte de cualquier órgano gubernamental; y la expropiación de la empresa por parte del gobierno" ${ }^{24}$. En este sentido, la teoría de atribución es más amplia de lo sugerido en base a la teoría del levantamiento del velo corporati$\mathrm{vo}^{25}$. Estos criterios parecen suficientemente similares en el arbitraje económico ${ }^{26}$.

Al mismo tiempo, la CIJ ha descartado que la sola creación de una entidad de derecho privado pueda privarle a una entidad de su carácter estatal. Así, en República de Irán c. Estados Unidos, confirmó que la "naturaleza de las actividades" ${ }^{27}$ de una entidad determinará si goza de inmunidad soberana y, por lo tanto, debe asumir las correspondientes responsabilidades. De Stefano critica, en general, la utilización de la "función pública" como único criterio de atribuibilidad, y argumenta que debería reemplazarse por "prerrogativa gubernamental"28, basada en ciertos elementos que se han usado para demostrar el control estructural de los órganos del Estado sobre la empresa: creación por ley o decreto; mandato de proveer un servicio público, manejar propiedad estatal; capacidad de demandar y ser demandada; presupuesto autónomo; cuentas con el banco central del Estado propietario; subsidios gubernamentales; ejercicio de un monopolio delegado y la facultad de determinar precios; nombramiento del directorio por el gobierno o fuerzas políticas; ministros como miembros del directorio, aplicabilidad del estatuto de funcionarios públicos; auditorías por las contralorías públicas; aprobación obligatoria de operaciones o decisiones; jurisdicción de tribunales administrativos; aplicabilidad la regulación sobre compras públicas; inmunidad y otros ${ }^{29}$.

Contrastando estos criterios con las Directrices de la OCDE sobre gobernanza de las empresas de propiedad del Estado, se puede notar que, si bien estas tienden a exigir una diferenciación clara entre el Estado y su empresa, no se podría deducir que su cabal implementación ha de significar la imposibilidad de atribuir sus actos u omisiones al Estado: el equilibrio entre el ejercicio "informado y activo", y "transparente y responsable" 30 de las funciones estatales de propietario y las indebidas interferencias políticas en la gestión de una $\mathrm{EPE}^{31}$ no excluye la posibilidad de que, según los criterios proporcionados arriba, estemos ante una hipótesis de control, incluyendo los incentivos apropiados para el respeto de los derechos humanos ${ }^{32}$.

\section{b. El Sistema Interamericano de Derechos Humanos}

En la jurisprudencia de la Corte IDH no se observaba discusión o argumentación sobre la atribución de las acciones u omisiones de las EPE al Estado hasta la sentencia Mue-

24 De Stefano (2020) pp. 79-80.

25 De Stefano (2020) p. 81.

26 Por ejemplo, Barnes (2019) Cortesi (2017), Wu (2017).

27 CIJ, Certain Iranian Assets (2019) párr. 89.

28 De STEFAno (20202) pp. 156-157, 158ss.

29 De Stefano (2020) pp. 154-157.

30 OCDE (2015) p. 14 y para. II.F, 18.

31 OCDE (2015) p. 15.

32 OCDE (2015) p. 60. 
lle Flores c. Perú, de $2019^{33}$. En ninguno de los casos anteriores que involucraban EPE, se proporcionaban argumentos sobre atribución, sino que simplemente se presumía, tanto en los votos de mayoría como en los de minoría. Al estudiar los casos en detalle, sin embargo, vemos que todos recaen en alguna de las hipótesis de atribución, sea por función o control.

Así, en el caso Abrill Alosilla y otros c. Perú, la Corte IDH no evaluó los actos de la empresa pública que supuestamente habría incidido en la adopción de una normativa dirigida como represalia a sus trabajadores, rebajando sus remuneraciones ${ }^{34}$, sino solo en base a los actos de los poderes ejecutivo y judicial ${ }^{35}$. De manera similar, en el caso Trabajadores Cesados de Petroperú y otros c. Perú, solo se analizó un problema de acceso a la justicia en relación con los derechos de los trabajadores; la Corte IDH no se pronunció -ni fue requerida a hacerlo- sobre la posible responsabilidad directa de los ministerios y EPE que habían despedido a sus trabajadores y funcionarios ${ }^{36}$. En este sentido, el caso no fue planteado como un problema sobre la atribuibilidad de actos de las EPE al Estado.

En Comunidad Kichwa de Sarayaku c. Ecuador, en cambio, la Corte IDH sí determinó actos de la empresa Petroecuador como atribuibles al Estado, en cuanto esta actuó, en su rol de contraparte en los contratos de concesiones, como órgano estatal a cargo de las concesiones petroleras del país ${ }^{37}$. Ciertamente, al tener Petroecuador facultades de fiscalización, e incluso de cierre de proyectos, el caso recae bajo los supuestos previstos en el artículo $5^{\circ}$ del Proyecto de Artículos, más específicamente, la función gubernamental, aunque el tribunal no haya hecho explícito este argumento. Es solo en Muelle Flores c. Perú que la Corte IDH aborda, por primera vez y solo puntualmente, la atribución en base a acciones de una EPE, analizando el proceso de su privatización. Determinó que una deuda de pensiones incurrida antes de la privatización era responsabilidad del Estado ${ }^{38}$.

En definitiva, al proporcionar tan pocos argumentos sobre atribución, el razonamiento de la Corte IDH parece insuficiente para nuestro análisis, aunque el resultado efectivamente sea el mismo que el que se produciría con un argumento basado en la costumbre internacional o los criterios desarrollados por su par europeo, como veremos en seguida.

Recientemente, la CIDH ha presentado un argumento basado en la presunción de atribuibilidad producto de que la propiedad del Estado sobre una EPE, según la CIDH, genera suficiente cercanía entre ambos, "a menos que se demuestre lo contrario" ${ }^{39}$, con la consecuente atribuibilidad, expresando en este sentido una presunción de atribución que la costumbre desconoce. Solo se ve reflejada la misma lógica -sin embargo, sin vínculo con el régimen de atribuibilidad- en los Principios Rectores de las Naciones Unidas sobre Empresas y Derechos Humanos del $2011^{40}$. Quedará por verse si la Corte IDH adopta este

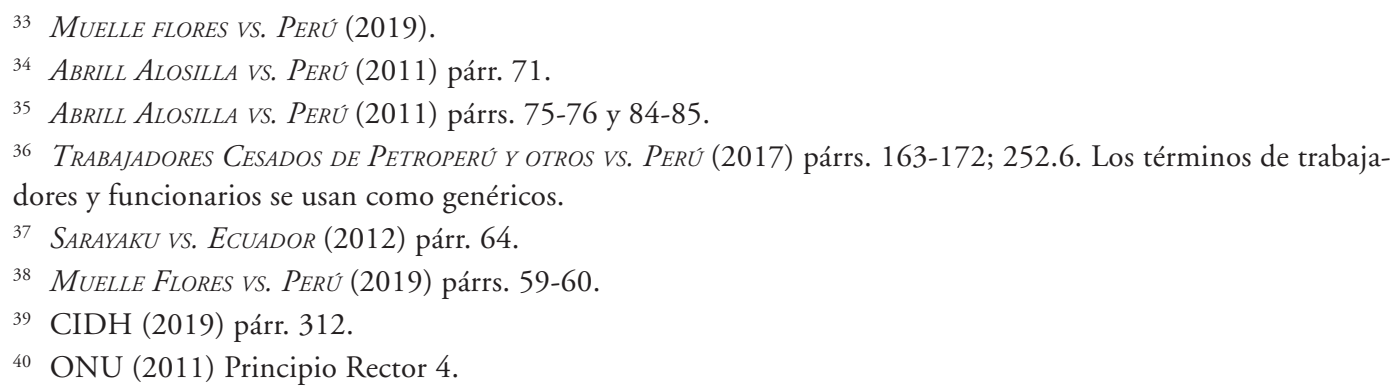


criterio sugerido por la CIDH: mientras hasta 2018, parecía muy posible y compatible con sus sentencias, la sentencia de Muelle Flores sugiere más de alguna duda al respecto, ya que, en ella, la Corte IDH recurrió explícitamente al criterio de control.

\section{c. La jurisprudencia del Tribunal Europeo de Derechos Humanos}

Por otro lado, el TEDH ha discutido asuntos de atribución de manera explícita, en decisiones de admisibilidad (artículo 34 del Convenio Europeo sobre Derechos Humanos) y menos explícitamente, en decisiones sobre el fondo.

El Tribunal considera que la propiedad estatal y el ejercicio de alguna función pública o gubernamental son criterios suficientes para concluir sobre la inadmisibilidad de una demanda que una EPE haya dirigido al TEDH ${ }^{41}$. En este sentido, refleja los criterios identificados por De Stefano en el derecho internacional general.

A diferencia del Proyecto, el TEDH toma en cuenta, de manera importante, la "naturaleza" de las actividades de la empresa como indicio de atribuibilidad. Por ejemplo, en el caso Islamic Republic of Iran Shipping Lines c. Turquía, el TEDH evaluó el estatus jurídico de la empresa y la naturaleza de las actividades que lleva adelante, además del grado de independencia de las autoridades políticas ${ }^{42}$, en un test que proviene de la decisión de admisibilidad del caso Radio France y otros c. Francia, del $2003^{43}$. Con resultado opuesto, en base a los mismos criterios, la Corte suele declarar inadmisibles los casos referentes a la privatización de "empresas de propiedad social" de los países del antiguo Pacto de Varsovia ${ }^{44}$. Estos criterios fueron confirmados posteriormente, por ejemplo, en Yershova c. Rusia, un caso sobre la contaminación causada por una planta de acero antiguamente de propiedad del Estado $^{45}$, enfatizando que el estatus jurídico de derecho interno no puede automáticamente eximir al Estado de responsabilidad ${ }^{46}$.

En cuanto al test de a atribución por control, el TEDH suele revisar el régimen constitucional, tributario, laboral, ambiental, de quiebra, corporativo, y el derecho administrativo aplicable, incluyendo los recursos de derecho público disponibles contra las EPE y las obligaciones de transparencia o de reportar al Estado, para evaluar si se rigen por normas distintas a las empresas privadas en la medida que estas podrían darle "prerrogativas exorbitantes" en relación a las otras empresas ${ }^{47}$. En caso de ser así, la balanza se inclina hacia la atribuibilidad, como se decidió en los casos Yershova c. Rusia ${ }^{48}$ y Luganskvugillya c. Ucrania ${ }^{49}$, donde la inaplicabilidad del derecho de quiebra y el control gubernamental

\footnotetext{
41 Véase, por ejemplo, JKP VODOVOD KRALJEVO VS. SERBIA (2018) párr. 26.

42 IsLAMIC REPUbliC OF IRAN SHIPPING VS. TURQUÍa (2007) párr. 79.

43 RADIO FRANCE y otros vs. FRANCIA (2003) párr. 26.

44 Véase por ejemplo, ZASTAVA IT TURS VS. SERBIA (2013).

45 YeRSHOVA VS. RUSIA (2010) párr. 55.

46 Yershova VS. Rusia (2010) párr. 56.

47 RADIO FRANCE y OtROS VS. FRANCIA (2003) párr. 26.

48 RADIO FranCE y otros vs. FranCIA (2003) párr. 62.

49 State Holding Company Luganskvugillya Vs. Ukraine (2009). Igualmente, MyKhaylenKY vs. UCRANIA (2004) párr. 45 y recientemente, KRNDIJA VS. SERBIA (2017) párr. 66 y BURMYCH VS. UCRANIA (2017) párr. 11 ss, así como VORONKOV VS. RUSIA (2015) párr. 47 y SiMAITIENĖ VS. LITUANIA (2017) párr. 53.
} 
sobre la empresa, respectivamente, evidenciaron el control del Estado. En Transpetrol c. Eslovaquia, en cambio ${ }^{50}$, se decidió en base a una "unidad en los intereses" entre la empresa y el gobierno, sustentado en el hecho que el Estado se hizo parte de los procesos internos a favor de la empresa ${ }^{51}$.

Finalmente, el caso Heinisch c. Alemania nos proporciona un criterio útil para comprender otro aspecto: el tribunal consideró que información sobre la calidad del cuidado de personas mayores en una residencia era de interés público, siendo esto "aún más evidente" tratándose de una empresa de propiedad del Estado que estaba a cargo de estos cuidados ${ }^{52}$. El interés público de saber sobre eventuales delitos cometidos en el cuidado pesaba más que la reputación e interés comerciales de la empresa ${ }^{53}$. Sin embargo, este criterio no fue reitera$\mathrm{do}^{54}$. Otro raciocinio aislado se manifiesta en Dimitar Yordanov c. Bulgaria, que sugiere que la fuerte regulación en un ámbito estratégico para el Estado podría en sí sugerir atribuibilidad $^{55}$; sin embargo, el criterio no ha sido confirmado en jurisprudencia posterior ${ }^{56}$.

En definitiva, la jurisprudencia del TEDH confirma los criterios del derecho consuetudinario sobre cuestión de la atribuibilidad. A pesar de no ser derecho aplicable en el sistema interamericano, aporta insumos para la interpretación analógica. Al desconocer, aún, los detalles de la teoría de atribuibilidad que ocupará la Corte IDH, parece razonable el ejercicio de evaluar CODELCO y ENAP con los criterios derivados en esta sección, ya que tienen su origen común en el Proyecto. Si encontramos atribuibilidad bajo estas hipótesis más estrictas, también la habría basada en el mero criterio de propiedad. Así, una mirada global a estos factores nos permite evaluar si las acciones u omisiones de CODELCO y ENAP, particularmente en materias de derechos humanos y ambientales, deben considerarse atribuibles directamente al Estado.

Los criterios relevantes que el análisis jurisprudencial nos ha permitido derivar son, entonces, el control de órganos del Estado sobre la EPE, evidenciado principalmente por la aplicación de regímenes de derecho público o especiales; la participación del poder ejecutivo en los directorios y, en menor medida, su injerencia en su constitución; el control sobre los presupuestos y las actividades diarias de las EPE; e indicios subsidiarios como la representación de la empresa en procesos judiciales a nivel nacional; la operación de la EPE en un monopolio ${ }^{57}$.

50 TRANSPETROL VS. ESLOVAQUIA 2004 (2011) párr. 60-66.

51 TRANSPETROL VS. ESLOVAQUiA 2004 (2011)párr. 72-74.

52 HeINISCH VS. ALEMANIA (2011) párrs. 71.

53 Heinisch vs. Alemania (2011) párr. 90. véase también RajaVuOri (2015).

4 LANGNER VS. ALEMANIA (2016).

5 Véase Dimitar YoRDANOV vs. BULGARIA (2018) párr. 60.

6 Dimitar Yordanov vs. Bulgaria (2018) párr. 65.

57 Véase también, en el mismo sentido que De Stefano (2020), Schönsteiner (2019) pp. 933-934. 


\section{RÉGIMEN DE EMPRESAS PÚBLICAS EN CHILE: DERECHO APLICABLE Y ATRIBUIBILIDAD}

A continuación, explicaremos los regímenes que, siendo comunes a las empresas analizadas en este artículo, son especiales en relación con las empresas que no son de propiedad estatal. A partir de estos elementos, además de los que identificaremos en cuanto al control del ejecutivo sobre las EPE, determinaremos en qué medida se deben atribuir al Estado de Chile las acciones y omisiones de CODELCO y ENAP. Por lo pronto, la mera existencia de regímenes especiales para las empresas de propiedad estatal sería, en principio, un indicio de atribuibilidad. Para ello, utilizaremos los criterios identificados en la sección 2.

Este estudio solamente revisa con detalle la hipótesis de control estatal, ya que ninguna de las dos empresas cumple funciones públicas o gubernamentales: se dedican a la explotación y exploración de yacimientos de propiedad del Estado, y la comercialización de sus productos en el caso de $\mathrm{CODELCO}^{58}$, y la exploración, explotación o beneficio de yacimientos que contengan hidrocarburos, y "en general, comercializar petróleo o gas" en el caso de ENAP 59.

\section{a. DeREChO CONSTITUCIONAL Y ADMINISTRATIVO}

Las Empresas del Estado están reguladas por el artículo 19 No 21 de la Constitución Política de la República (“CPR”), cuyo inciso 2o establece una reserva legal de quórum calificado para la habilitación a que el Estado desarrolle actividades económicas, y determina como regla general para sus actividades la aplicación del derecho común, cuyas excepciones también están sometidas a dicha reserva. La doctrina tradicional interpreta esta reserva en función del principio de subsidiariedad ${ }^{60}$ y la especialidad del giro ${ }^{61}$.

Según el artículo $1^{\circ}$ inciso 2o de la Ley No 18.575 de 1986 sobre Bases Generales de la Administración del Estado ("LOCBGAE"), las "empresas públicas creadas por ley" son parte de la Administración. Dicha ley se aplica íntegramente a las EPE, excepto los títulos sobre Normas Especiales, por un lado, y Participación Ciudadana en la Gestión Pública, por el otro, según lo dispuesto en los artículos 21 inciso $2^{\circ}$ y 75 .

En general, a pesar de que sean regidas por el derecho común ${ }^{62}$, a las EPE se le aplican todas las normas de la Administración que no estén expresamente exceptuadas ${ }^{63}$. Así,

\footnotetext{
58 Artículo 3 del Decreto Ley No 1.350 que crea CODELCO, de 1976.

59 Artículo $2^{\circ}$ del Decreto con Fuerza de Ley No 1 del Ministerio de Minería (1986), que fija texto refundido, coordinado y sistematizado de la Ley No 9.618, que crea la Empresa Nacional del Petróleo. La hipótesis del conflicto de interés por funciones de regulador en relación con la geotermia solo mantenía su vigencia mientras no se hubiera reformado el gobierno corporativo de la empresa, véase PARDOW y TORRES (2016), p. 316.

60 Véase, por ejemplo, Silva Bascuñán (1997) pp. 51-52; López (2006) pp. 46-49; Fermandois (2006) pp. 7173; Navarro (2000) pp. 42-44; Soto Kloss (1999) p. 124. Recientemente, Loebenstein (2018). En sentido contrario, Pardow y Vallejo (2008) pp. 135-156.

${ }^{61}$ Véase, por ejemplo, Fermandois (2006) p. 228, Aróstica (2001) pp. 109 y 115; Soto Kloss (2000) pp. 239 y ss.; Garrido (1966) pp. 84 y ss.; NAVArro (1995) pp. 263-275; Covarrubias (2004) pp. 253 y ss.; y Aróstica (2001) pp. 115 y 116.

62 Véase también OCDE (2015) p. 13.

63 Ley de Acceso a la Información Pública, LOCBGAE; Ley No 18.918 LOC del Congreso Nacional (Artículo 9 y 10); Ley No 19.628 sobre Protección de la Vida Privada (Artículo 1); Ley No 10.336 LOC de la CGR.
} 
en el caso de la Ley No 19.880 sobre Bases de los Procedimientos que rigen a los Órganos de la Administración del Estado (LBPA), el artículo 2 señala una serie de instituciones que se someterán a la ley, pero no menciona a las EPE, a diferencia de lo que hace el artículo 1 de la LOCBGAE. Esto permitiría concluir que la LBPA no es aplicable a las empresas del estado $^{64}$. Tampoco rige el Decreto Ley No 1.263 sobre Administración Financiera del Estado, de conformidad con el artículo 11 inciso $5^{\circ}$ de la Ley No 18.196 que establece Normas Complementarias sobre Administración Financiera. Quedan exceptuados además los artículos 29 y 44 del Decreto Ley No 1.263, que regulan el traspaso de utilidades de las empresas a las rentas generales de la Nación y obligan a que Hacienda autorice los actos que de algún modo puedan comprometer el crédito público, respectivamente.

Desde una perspectiva estructural, por tanto, se puede decir que las EPE se rigen según el funcionamiento del mercado en cuanto a sus operaciones, pero según el derecho administrativo en cuanto a su responsabilidad. Esta diferenciación, inexistente para las empresas privadas, sugiere que estamos ante un régimen especial para las empresas públicas que se caracteriza por un mayor control estatal sobre estas, en comparación con el sector privado. Por tanto, estaríamos ante un régimen que sugiere, en principio, atribuibilidad.

\section{b. ReCURSOS DE DERECHO PÚBlico}

Según los criterios de atribuibilidad enunciados en la sección 2, la aplicabilidad de recursos de derecho público es un fuerte indicio que una EPE debería considerarse "parte" del Estado. En Chile, la evidencia es mixta. La responsabilidad por falta de servicio, contenida en el artículo 42 de la LOCBGAE, no aplica a las EPE. Así lo ha reconocido la jurisprudencia $^{65}$. En cambio, el régimen aplicable es el de la responsabilidad extracontractual de los artículos 2314 y siguientes del Código Civil ${ }^{66}$, lo que constituye un indicio en contra de la atribuibilidad, ya que se trata a empresas privadas y de propiedad del Estado por igual.

En cambio, la jurisprudencia de la Corte Suprema sobre la aplicabilidad del amparo económico ha sido vacilante a lo largo de los años ${ }^{67}$, en el sentido de existir falta de claridad si la acción abarca ambos incisos del artículo 19 No 21 de la CPR o solo el segundo ${ }^{68}$. Si abarcara ambos incisos, la acción podría ser dirigida tanto contra privados como contra EPE, puesto que el inciso primero no limita la prohibición solo a estas últimas; mientras que, si abarcara solo el inciso segundo, sí se restringiría la acción solo a las EPE. La jurisprudencia reciente se decanta por esta última opción ${ }^{69}$. Empresas públicas han sido condenadas en sede de amparo económico ${ }^{70}$. Se configura de este modo una diferencia impor-

\footnotetext{
64 Ahumada (2003) p. 117; Jara (2008) p. 293.

65 Mardones Cepeda con Banco Estado (2008).

66 Mardones Cepeda con Banco Estado (2008).

67 Para análisis de dicha jurisprudencia, ver, Ponce de LeÓn (2014), pp. 97-126; Nogueira (2010) pp. 415442; Bassa y Viera (2012) pp. 661-683; Hernández (2010) pp. 443-466.

68 PONCE DE LEÓN (2014) pp. 106-108.

69 Ponce de LeÓn (2014) p. 109.

70 Asimet A.G. con Corporación Nacional del Cobre (1993), Asociación Nacional de la Prensa A.G. con Empresa de Transporte de Pasajeros Metro S.A. (2000), Chilexpress S.A y línea Aérea Nacional S.A. con Banco del Estado (1995), Farías Zapata con Empresa Portuaria de Iquique (2003), Incomin S.A.
} 
tante entre EPE y empresas privadas, por existir un recurso de derecho público solo contra las EPE. Esta diferencia es un indicio a favor de la hipótesis de atribuibilidad en el derecho internacional público.

En relación con la acción de nulidad de derecho público, la Corte Suprema ha conocido casos impetrados contra EPE sin cuestionar su legitimidad pasiva ${ }^{71}$ y reconociendo, al menos implícitamente, que las mismas pueden dictar actos administrativos impugnables por esta vía ${ }^{72}$. Del tenor del artículo 7 de la CPR, empresas privadas no podrían ser sujetos pasivos de una acción de nulidad de derecho público. En consecuencia, en este ámbito también se configuraría una distinción entre EPE y empresas privadas. Ambas líneas de jurisprudencia constituyen indicios a favor de la atribuibilidad de responsabilidad según los criterios establecidos a partir de la jurisprudencia internacional, mientras la interpretación de la responsabilidad por falta de servicio matiza esta conclusión.

\section{c. Contraloría General de la República y Congreso}

El ya referido artículo 11 inciso 5 de la Ley No 18.196 determina que, en relación con las EPE, se aplican las potestades de la CGR que dispone la Ley No 10.336 Orgánica Constitucional de la Contraloría General de la República (LOCCGR). Al respecto, los artículos 98 de la Constitución y 16 inciso $1^{\circ}$ de la LOCCGR establecen que las EPE están sometidas a la fiscalización de la $\mathrm{CGR}^{73}$, con independencia de su forma de constitución.

El estándar de control, sin embargo, varía dependiendo del tipo de empresa. Tanto las sociedades estatales ${ }^{74}$ como las empresas públicas como ENAP y CODELCO, están sometidas a la fiscalización de la CGR, pero solo las actuaciones de estas últimas deben pasar por el procedimiento de toma de razón ${ }^{75}$, o sea, un control previo de parte del órgano contralor. En particular, el artículo 11 de la Resolución No 1600 del 2008 de la CGR establece que la toma de razón procederá (solamente) respecto de las "resoluciones relativas a la constitución, participación, modificación y retiro o extinción de personas jurídicas, y a la adquisición de acciones u otros títulos de participación en sociedades" ${ }^{\text {. }}$. La distinción es relevante, por cuanto las filiales de CODELCO y ENAP suelen adoptar la estructura de

con Enami (2000), Mardones Cepeda con Banco del Estado (2008), Portuaria Anden San Antonio con Empresa Portuaria San Antonio (2009), Sociedad Visal Ltda. con Empresa Portuaria de Arica (2007), y Socolibros Ltda. con Editorial Jurídica de Chile. (1997). Los casos se obtuvieron de la base jurisprudencial de Microjuris. En el buscador, se ingresaron las voces "Empresas del Estado" y "Amparo económico". De la lista arrojada se seleccionaron los casos que acá se ilustran.

71 Ver casos Sociedad Visal Ltda. con Empresa Portuaria de Arica (2007) y Portuaria Anden San Antonio con Empresa Portuaria San Antonio (2009).

72 Sociedad Visal Ltda. con Empresa Portuaria de Arica (2007) c.11. Véase también Cordero (2015) p. 260.

73 Dictamen No 18.850, del 2017.

74 Las sociedades del Estado "se caracterizan por constituirse, organizarse y funcionar de acuerdo a las disposiciones del derecho común, en tanto que el derecho público solo regirá a su respecto en materias específicas vinculadas principalmente al control de algunos de sus actos, en la mayoría de los casos relativos al manejo de sus recursos financieros". Ver LATORRE, Patricio (2008), p. 255. En otras palabras, son una sociedad de derecho privado, cuya propiedad pertenece al Estado, y no están reguladas por una ley en particular, ni sometidas al control de órganos en su actividad normal, salvo en cuanto a lo que tiene que ver con su patrimonio.

75 Véase Dictamen 18.589, del 2017.

76 Resolución No 1.600 de la Contraloría General de la República (6 de noviembre de 2008). 
sociedad anónima con participación de la empresa principal, y, por tanto, se eximen de la revisión previa de la CGR. Dependería de la estructura de control operativo si sus acciones u omisiones resultaran atribuibles al Estado de Chile según las hipótesis del derecho internacional general y especial ${ }^{77}$.

Con todo, el rol de la CGR en relación con las empresas públicas es preventivo. Así, sus acciones gozan del visto bueno del Estado, y este tiene que hacerse cargo de las decisiones que valida. Al mismo tiempo, habilita al Estado ejercer acciones de prevención requeridas por artículo 1.1. de la Convención Americana de Derechos Humanos (“CADH”), tal como ha sido establecido en la jurisprudencia constante de la Corte IDH en materia ambiental y de derechos humanos ${ }^{78}$. Las potestades de la CGR en esta materia permiten al Estado revisar una serie de elementos internos de las empresas públicas, como los acuerdos colectivos a que las empresas han llegado con sus trabajadores ${ }^{79}$. Esta facultad no existe sobre las empresas privadas por lo que sí constituye un importante indicio de atribuibilidad. Además, la CGR evaluó si el nombramiento de una autoridad empresarial se ajustó a derecho $^{80}$; si los directores se consideran funcionarios públicos ${ }^{81}$, si un contrato o un proyecto son lícitos ${ }^{82}$, y si corresponde indemnizar por el despido de los directores de las empresas públicas $^{83}$, argumentando que CODELCO no tiene libre disposición de sus recursos, por ser estos fondos públicos ${ }^{84}$.

En definitiva, el control realizado por la CGR sobre CODELCO y ENAP es suficientemente intenso como para apoyar fuertemente la hipótesis de atribuibilidad al Estado de los actos y omisiones de las EPE.

\section{d. Derecho laboral, QUiebra e insolvencia, tributario y NORMAS SOBRE TRANSPARENCIA}

Si bien los trabajadores de las empresas públicas ostentan el cargo de funcionarios públicos ${ }^{85}$, las leyes que crean $\mathrm{CODELCO}^{86}$ y $\mathrm{ENAP}^{87}$ disponen expresamente que las relaciones laborales en su interior se rigen por el Código del Trabajo. No obstante, existen algunas excepciones. Por ejemplo, las empresas que obtengan un 50\% o más de su financiamiento por parte del Estado están excluidas de la facultad de negociar colectivamente,

\footnotetext{
$77 \mathrm{Al}$ analizar el estándar que CGR aplica a las sociedades estatales, vemos que incluso en estos casos, en que la fiscalización es de menor intensidad que la que recae sobre las EPE, el control realizado permite al Estado conocer la "regularidad de sus operaciones" y "hacer efectivas las responsabilidades de sus directivos o empleados". Por ejemplo, Dictamen No 83.133 del 2016. Agradecemos a Marco Silva esta observación.

78 Opinión Consultiva No 23 (2017) párr. 118 y 127.

79 Por ejemplo, Dictamen No 18.850 de 2017.

80 Dictámenes No 16.449 de 2018 y No 13.564 de 2018.

81 Dictamen No 23.608 de 2015, véase también Brower (2016).

82 Dictamen No 45.162 de 2017.

83 Dictámenes No 15.759 de 2017 y No 18.850 de 2017.

84 Dictamen No 15.759 de 2017.

85 Véase Dictamen No 16.164 del 1994.

86 Decreto Ley No 1.350 de 1976, Artículo 25.

87 Decreto con Fuerza de Ley No 1 de 1986, Artículo 15.
} 
de conformidad con lo dispuesto en el artículo 304 inciso $3^{\circ}$ del Código del Trabajo. En definitiva, los regímenes aplicables de derecho laboral, por sí solos, sugieren que no habría atribuibilidad.

La lectura del ya citado artículo 19 No 21 de la CPR, podría insinuar que las empresas públicas, en ausencia de legislación especial, se deberían regir por las normas comunes de insolvencia, contenidas fundamentalmente en la Ley No 20.720 sobre Insolvencia y Reemprendimiento. No obstante, la jurisprudencia ha establecido la imposibilidad de que una empresa pública sea declarada en insolvencia, sobre la base del principio de continuidad y permanencia en la provisión de necesidades públicas. Esto obliga mantener funcionando a la empresa hasta que la ley le ponga término ${ }^{88}$. La mencionada interpretación jurisprudencial confirma la aplicación de un régimen especial, desalentado por las Directrices de la $\mathrm{OCDE}^{89}$, y otro indicio de que sus acciones y omisiones son directamente atribuibles al Estado.

En cuanto al régimen tributario, CODELCO y ENAP se rigen por el sistema general, aunque no están sujetas a los impuestos Global Complementario ni a la Renta de Primera Categoría ${ }^{90}$. El artículo $2^{\circ}$ del Decreto Ley No 2.398 sobre Normas Complementarias sobre Administración Financiera ${ }^{91}$ establece un impuesto especial, cuya tasa es $40 \%{ }^{92}$. CODELCO y ENAP están sujetas a este impuesto ${ }^{93}$.

Como explica el Ordinario del Servicio de Impuestos Internos (SII), las EPE no están sujetas a los impuestos Global Complementario ni a la Renta de Primera Categoría ${ }^{94}$. En todo caso, el artículo 26 del Decreto Ley que crea CODELCO establece que la empresa se rige por el artículo 2 del Decreto Ley 2.398, que establece un impuesto a la renta especial, de 40\%, para las EPE y las sociedades estatales. Estas normas pueden ser consideradas como un indicio de atribuibilidad, ya que muestran una relación especialmente intensa entre el Estado y las EPE, por otorgarles una carga tributaria superior y distinta a las que recae sobre las empresas privadas, afectando su competitividad. En el caso de CODELCO encontramos además una norma especial en la controvertida y, a partir de 2019, derogada Ley de Aporte Reservado del Cobre que nos da un indicio adicional de un trato distinto en materia tributaria, hasta 2032 cuando finalice el financiamiento directo de las fuerzas armadas por parte de CODELCO ${ }^{95}$.

Finalmente, según los artículos 2 y 7 de la Ley No 20.285 sobre Acceso a la Información Pública, a las EPE les es aplicable la “Transparencia Activa”, en virtud de la cual tienen el deber de mantener publicada en su página web información relativa a sus elementos estructurales. En contraposición, no se le aplican los deberes de transparencia pasiva, que se

\footnotetext{
88 Ver Incomin S.A. con Enami (2000) y Farías Zapata con Empresa Portuaria de Iquique (2003).

89 OCDE (2015) p. 13.

90 Servicio de Impuestos Internos (2018) pp. 3 y 4.

91 Ministerio de Hacienda, 29 de noviembre de 1978, sobre Normas Complementarias de Administración Financiera y de Incidencia Presupuestaria, Artículo 2.

92 Decreto Ley 824 de 1974.

93 Ver CODELCO (2018) p. 185 y ENAP (2018) p. 350 (p. 40 de las notas a los EEFF).

94 Servicio de Impuestos Internos (2018) pp. 3 y 4.

95 Ley No 13.196 de 1958, que originalmente era de carácter reservado, pero cuyo contenido fue hecho público por la Ley 20.977 (2016). Derogado, con plazo de 12 años, por Ley No 21.174 de 2019.
} 
entienden como la obligación de entregar la información solicitada por las personas, según el procedimiento establecido en la misma ley. De esta forma, las EPE están en una posición intermedia en relación con la regulación de transparencia, al igual que la CGR y el Banco Central. Eso, sin perjuicio de compromisos voluntarios en materia de transparencia, o de alianzas como la que tiene ENAP con Chile Transparente, indica regulación diferenciada en comparación con la aplicable a empresas privadas.

\section{e. REPRESENTACIÓN JUDICIAL}

En Chile, el Fisco es representado por el Consejo de Defensa del Estado (“CDE”). En la ley que lo crea $^{96}$ no hay normas que le den la facultad de representar las EPE. A partir de la información recibida en virtud de la Ley de Acceso a la Información Pública ${ }^{97}$, se analizaron las últimas 100 causas en las que el CDE ha participado y que también una de las dos empresas aquí analizadas fuera parte del juicio. De estas 100 causas, 81 eran conflictos entre CODELCO o ENAP y el Fisco, este último representado por el CDE. Entre las 19 causas restantes, 12 fueron juicios penales contra particulares, por lo que no consideramos que sean relevantes para el análisis. Por último, en seis causas ${ }^{98}$, todas civiles, el Fisco y una de las EPE fueron demandados por separado, y responden de forma separada a estas demandas ${ }^{99}$. De esta forma, vemos que el eventual indicio de atribuibilidad, consistente en que el Estado represente judicialmente a la empresa ${ }^{100}$, no se cumple en la ley ni en la práctica y constituye un indicio en contra de la atribuibilidad en el derecho internacional.

Considerando estos elementos, podemos afirmar que las acciones y omisiones de CODELCO y ENAP son atribuibles al Estado de Chile en virtud del régimen regulatorio aplicable, que es distinto al estatuto jurídico de las empresas privadas en aspectos tan relevantes como la disponibilidad de algunos recursos de derecho público; el trato de los directores de la empresa como funcionarios públicos; la inaplicabilidad del derecho de quiebra; tributación diferenciada y transparencia. Sin embargo, la evidencia, presentada hasta ahora, no parece concluyente. Los indicios en contra de la hipótesis de atribuibilidad son importantes: la aplicación del derecho laboral, la clara excepcionalidad de los recursos públicos para que un tercero las demande, y la consistente separación de la representación jurídica de la empresa y del Estado. Aunque estos indicios no parecen tener suficiente peso para contrarrestar la lógica principal de la responsabilidad directa, será la normativa y práctica en relación con el control del poder ejecutivo sobre la EPE la que deberá mostrar por qué lado se inclina la balanza.

\footnotetext{
96 Decreto con Fuerza de Ley No 1 del Ministerio de Hacienda de 2016.

97 Solicitud No AX001T0000695 al Consejo de Defensa del Estado, de fecha 2 de enero de 2019.

98 Claussen Calvo con Fisco de Chile y CODelCo Chile División Chuquicamata (2018), Alcayaga con Fisco; Corp. Nac. del Cobre (2000), Fonseca con Corporación Nacional del Cobre - Fisco (2001), Bautista con Fisco (2011), Quinzacara Toro con ENAP y Fisco (2012), Torres con ENAP (2004) y Bozinovic y otro con Empresa Nacional de Petróleos y otro (2012).

99 Hay una causa el Fisco no figura como parte en el sistema electrónico del Poder Judicial, a pesar de estar en la lista de resultados. Por tanto, no fue considerada Corporación Nacional del Cobre con Inversiones AnGLOAMERICAN SUR S.A. Y OTROS (2011).

100 Véase Transpetrol vs.. Eslovaquia (2011) párr. 74.
} 


\section{CONTROL DEL PODER EJECUTIVO SOBRE LAS EPE}

La evaluación del control del Estado sobre CODELCO y ENAP se realizará teniendo en consideración tres elementos. Primero, se analizarán las potestades de los órganos del Estado de modificar los estatutos y de nombrar, fiscalizar y remover a los miembros del directorio, y se evaluará cuán remoto es ese control. Segundo, veremos las facultades que tienen algunos órganos administrativos en relación con los presupuestos de la empresa y otros mecanismos que inciden sobre la economía. Finalmente, se estudiarán los procedimientos de aprobación de las actividades y proyectos que la requieren.

En cuanto a la ponderación de estos criterios, se considerará la suma de los elementos. Si hubiera participación significativa y directa del ejecutivo en los directorios, o control de las actividades diarias o decisiones estratégicas, se considerará como prueba de la hipótesis de atribución por control, por su impacto directo en las actividades y la supervisión.

El análisis presentado aquí se refiere, principalmente, al control tal como quedó establecido después de las reformas de gobierno corporativo de CODELCO y de ENAP, mediante las cuales se pretendió - para adecuar la legislación a las recomendaciones de la OCDE ${ }^{101}$ - desvincular al gobierno de la "gestión cotidiana" de la empresa, "dándole [a esta] autonomía operativa para alcanzar sus objetivos"102 y propender a que el directorio "ejerza sus funciones bajo un estándar mínimo de independencia"103.

\section{a. ACCIONISTAS, JUNTA DE ACCIONISTAS Y DIRECTORIO}

Para ambas empresas, la junta de accionistas está conformada por el/la Presidente/a de la República en representación del pueblo chileno ${ }^{104}$. El o la presidente/a podrá delegar estas funciones total- o parcialmente en los ministerios de Hacienda y Minería, y Hacienda y Energía, respectivamente ${ }^{105}$. Además, el ejecutivo tiene la potestad de aprobar y modificar, por decreto supremo conjunto de estos, los Estatutos de la empresa ${ }^{106}$. Considerando que los estatutos de una empresa determinan su estructura y los límites a los que están sujetos sus órganos, estas facultades dan cuenta de una sujeción fuerte y sostenida (no solo inicial) de CODELCO y ENAP al Estado. Particularmente, la ausencia de una "entidad de coordinación" 107 en la estructura de gobernanza -tal como para otras EPE existe el Sistema de Empresas Públicas (SEP) - refuerza esta hipótesis de sujeción fuerte.

Al Presidente o Presidenta de la República le corresponde designar también a los nueve directores de $\mathrm{CODELCO}^{108}$ y los siete de ENAP. De estos, tres - dos para ENAP-

\footnotetext{
101 Historia de la Ley 21.025 (2017) p. 4.

102 Historia de la Ley 21.025 (2017) p. 5.

103 Historia de la Ley 21.025 (2017) p. 5.

104 Artículo 11 A del Decreto Ley No 1.350 de 1976 para CODELCO y artículo 14 del Decreto con fuerza DE LEY No 1 de 1987, para ENAP.

105 Artículo 11 B del Decreto Ley No 1.350 de 1976 para CODELCO y artículo 3 del Decreto con fuerza DE LEY No 1 de 1987, para ENAP.

106 Artículo 11 del Decreto Ley No 1.350, de 1976.

107 OCDE (2015) p. 15.

108 Artículo 8º del Decreto Ley No 1.350, de 1976.
} 
son nombrados directamente por el/la Presidente, dos - uno para ENAP- representan a los trabajadores y son elegidos en base a quinas separadas propuestas por estos; y los otros cuatro los elige el/la Presidente/a, a partir de ternas propuestas por el Sistema de Alta Dirección Pública. Entre los directores de CODELCO y ENAP, respectivamente, el/la Presidente/a elige a quien preside el directorio. En el caso de ENAP, los directores solo pueden ser reelegidos una sola vez ${ }^{109}$.

Son incompatibles con la membresía en el directorio de $\operatorname{CODELCO}^{110}$ y ENAP ${ }^{111}$ ciertos cargos públicos. Estas reglas aumentan la distancia entre el directorio respectivo y el ejecutivo, por lo cual se debe considerar un indicio en contra de una hipótesis de atribución. Con anterioridad a las reformas a los Estatutos de las dos empresas públicas, los requisitos para la atribuibilidad se cumplían con la mera presencia de ministros en los directorios de las empresas ${ }^{112}$.

Por otra parte, los directorios no pueden ser revocados en su totalidad ${ }^{113}$, lo que limita la intensidad del control del poder ejecutivo. La ley dispone que los dos directores que son de libre elección del/la Presidente/a de la República, pueden ser, en el caso de ENAP, removidos sin expresión de causa por dicha autoridad ${ }^{114}$. Los otros, nombrados mediante alguno de los otros dos mecanismos, solo pueden ser removidos fundadamente por el/la Presidente de la República ${ }^{115}$. La remoción de directores de CODELCO, en cambio, no es una facultad discrecional de el/la Presidente, sino que está supeditada a las causales y el procedimiento establecidos en el Decreto Ley ${ }^{116}$, y debe ser confirmada por la Corte de Apelaciones de Santiago.

En conjunto con la selección de los y las directores mediante el Sistema de Alta Dirección Pública, la aprobación por parte de la Corte de Apelaciones aliviana la subordinación de la empresa a los órganos políticos, lo que no opera de la misma forma respecto de ENAP, puesto que no se requiere un proceso ante tribunales para la remoción de los directores. En este sentido, la injerencia de los órganos del poder ejecutivo es mayor en el caso de ENAP.

Finalmente, la remuneración del directorio es establecida por el Ministerio de Hacienda y debe ser revisada por la misma cartera con una periodicidad máxima de dos años ${ }^{117}$. Tal como la dependencia presupuestaria en general, que revisaremos en la siguiente sección, esto constituye un indicio a favor de la atribuibilidad.

\footnotetext{
109 Artículo $3{ }^{\circ}$ del Decreto con fuerza de Ley No 1 de 1987 , en contraste con artículo $8^{\circ}$.

110 Artículo 80 A y B del Decreto Ley No 1.350 de 1976.

111 Ver Artículo 6 del Decreto con Fuerza de Ley No 1 del Ministerio de Minería (1986).

112 Véase, por ejemplo, Parra (2017), OCDE (2015) p. 16.

113 Artículo $3^{\circ}$ c) del Decreto con Fuerza de Ley No 1 del Ministerio de Minería (1986) para ENAP, y Artículo $8^{\circ}$ c) del Decreto Ley No 1.350 de 1976 para CODELCO.

114 Artículo 7o Inciso Penúltimo del Decreto con Fuerza de Ley No 1 del Ministerio de Minería (1986).

115 Artículo 7o Inciso Final del Decreto con Fuerza de Ley No 1 del Ministerio de Minería (1986).

116 Artículo 8º C del Decreto Ley No 1.350 de 1976.

117 Artículo $3^{\circ}$ inciso 8o del Decreto con Fuerza de Ley No 1 del Ministerio de Minería (1986).
} 
En definitiva, el sistema de nombramientos solo es parcialmente "bien estructurado y transparente" 118 , y así, no solo contraría las recomendaciones de la OCDE, sino también constituye un indicio de atribuibilidad.

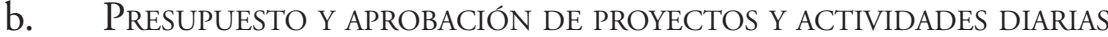

Son dos las formas en que se manifiesta el control estatal sobre los presupuestos. Deben formarse presupuestos de operación, de inversiones y de contratación, desembolso y amortización de créditos, los que son operados a través de un presupuesto anual de caja ${ }^{119}$. La ley exige que estos sean aprobados por los Ministerios de Hacienda y Minería en caso de $\mathrm{CODELCO}^{120}$; y de Hacienda y Energía en el caso de ENAP ${ }^{121}$. Los ministerios, entonces, realizan un control de carácter estructural a los presupuestos anuales.

Además, los ministerios controlan elementos cotidianos del funcionamiento de las empresas, al tener que aprobar los créditos que estas contraten -solo exigido para CODELCO_ ${ }^{122}$, los contratos de arrendamiento a largo plazo no revocables ${ }^{123}$, cualquier aporte de capital a sociedades o empresas de cualquier naturaleza y los depósitos o adquisiciones de instrumentos en el mercado de capitales ${ }^{124}$. De tal forma, todo acto de las empresas estatales que pueda, de cualquier manera, comprometer el crédito público, debe contar con la autorización previa del Ministerio de Hacienda ${ }^{125}$.

En cuanto a los proyectos de inversión que no están considerados en los presupuestos anuales, estos deben ser aprobados por los directorios respectivos, luego son revisados por Cochilco en el caso de CODELCO y por el Ministerio de Energía en el caso de ENAP, y finalmente requieren el visto bueno del Ministerio de Desarrollo Social ${ }^{126}$. La aprobación o rechazo del plan ambiental y comunitario se expide mediante decreto conjunto de los Ministerios de Hacienda y de Minería o Energía, respectivamente ${ }^{127}$, un aspecto que es de suma relevancia para los derechos humanos y ambientales ${ }^{128}$. El directorio debe además presentar un plan de desarrollo y negocios ${ }^{129}$ cuya aprobación o rechazo se realiza mediante decreto conjunto de los Ministerios de Hacienda y de Energía ${ }^{130}$. El plan debe considerar, a lo menos, los objetivos y metas de rentabilidad de la Empresa, los planes de inversión y desarrollo, y las directrices o propuestas de creación y disolución de

\footnotetext{
118 OCDE (2015) p. 16.

119 Artículo $11^{\circ}$ Inciso 2o de la Ley 18.196 de 1982 para ENAP y Artículo 13 Decreto Ley No 1.350 de 1976 para CODELCO

120 Artículo 17 o del Decreto Ley No 1.350 de 1976.

121 Artículo $11^{\circ}$ Inciso 3o de la LEY 18.196 de 1982 para ENAP.

122 Artículo 9o i) del Decreto Ley No 1.350 de 1976.

123 Artículo 24 Inciso 2o de la LeY 18.482 de 1985.

124 Artículo 3 Inciso 2o del Decreto Ley 1.056.

125 Artículo 44 del Decreto Ley 1.263.

126 Artículo 24 Inciso 3o de la LeY 18.482 de 1985.

127 Artículo 24 Inciso 3o de la LeY 18.482 de 1985

128 CODELCO (2008).

129 Artículo 90 Inciso $1^{\circ}$ del Decreto con Fuerza de Ley No 1 del Ministerio de Minería de 1986.

130 Artículo $9^{\circ}$ Inciso $1^{\circ}$ del Decreto con Fuerza de Ley No 1 del Ministerio de Minería de 1986.
} 
filiales o sociedades con terceros y todas las decisiones económicas de endeudamiento o asociaciones con otras empresas ${ }^{131}$.

En el caso específico de ENAP, el control del poder ejecutivo sobre la empresa se evidencia además en la regulación de los Contratos Especiales de Operación Petrolera mediante decreto del Ministerio de Energía ${ }^{132}$ que debe autorizar las enajenaciones de hidrocarburos y de derechos contractuales del contratista. Podrá también limitar las exportaciones de gas natural. Adicionalmente, todos los decretos estudiados establecen Comités de Coordinación para supervisar diversos aspectos del contrato. Los representantes del poder ejecutivo en los comités son designados por el Ministro de Energía. Si bien carecemos de información detallada sobre las atribuciones de los comités, puesto que estas se especifican en contratos que no están públicamente disponibles, el decreto debe establecer ciertas bases que injieren en la explotación misma, como acordar la producción máxima eficiente del yacimiento o pozo. Finalmente, los decretos establecen ocho causales de término anticipado del contrato, de las cuales seis son declaradas por el Ministerio de Energía. En consecuencia, ENAP no determina cuánto produce, encontrándose la aprobación de tales materias sometida al control del poder ejecutivo; todas las decisiones estratégicas importantes requieren su aprobación y, por tanto, constituye un fuerte indicio para la atribuibilidad.

Así, las decisiones más importantes para la empresa no se toman en el directorio, sino en su Junta de Accionistas, a saber, la Presidencia de la República o el ministerio a que delegue, tal como se resume en Tabla 1. Por tanto, a pesar del distanciamiento de los directorios del ejecutivo en cuanto a su composición y en parte, a su remoción, se confirma un involucramiento estatal significativo en el control de las empresas, por lo tanto, la hipótesis que las acciones y omisiones de CODELCO y de ENAP son atribuibles al Estado en el derecho internacional.

Las razones que podrían justificar una conclusión contraria a la atribuibilidad, como la política de no invocar inmunidad a favor de las EPE, o de aplicarles el derecho de sociedades, laboral o de libre competencia, no pueden desvirtuar la realidad del estrecho control, incluso en decisiones diarias, que ejerce el poder ejecutivo sobre las dos empresas. Eso es especialmente relevante en cuanto este control se extiende, explícitamente, sobre la evaluación de impacto regional, ambiental y de derechos humanos de los proyectos. Este elemento hace inclinar la balanza a favor de la responsabilidad internacional directa del Estado de Chile por eventuales violaciones causadas por sus acciones u omisiones.

131 Decreto con Fuerza de Ley No 1 del Ministerio de Minería de 1986.

132 La muestra de los decretos utilizados se obtuvo de www.leychile.cl. En el buscador, se ingresó la voz "contrato especial operación". De los resultados obtenidos, se descartaron todos aquellos que no fueran decretos, o que siendo decretos se refieren a otras materias. Obtuvimos cinco decretos: números 11, 122, 123, 125 y 126 , todos del 2012 y del Ministerio de Energía. Los cinco decretos son prácticamente idénticos. Lo dicho en el párrafo se obtiene de ellos. 
TABLA 1

Criterios de atribuibilidad en CODELCO y ENAP133

\begin{tabular}{|c|c|c|c|c|c|}
\hline & \multicolumn{5}{|c|}{ CONTROL } \\
\hline & $\begin{array}{c}\text { Control } \\
\text { Presupuestario }\end{array}$ & $\begin{array}{l}\text { Control diario } \\
\text { / aprobación } \\
\text { proyectos }\end{array}$ & $\begin{array}{l}\text { Composición } \\
\text { / selección } \\
\text { / remoción } \\
\text { directorio } \\
\end{array}$ & $\begin{array}{c}\text { Sujeto a CGR } \\
\text { y Cámara de } \\
\text { Diputados }\end{array}$ & $\begin{array}{l}\text { Función } \\
\text { pública }\end{array}$ \\
\hline CODELCO & SI, estrecho & $\begin{array}{l}\text { Menor desde } \\
\text { 2009, pero } \\
\text { control de } \\
\text { proyectos }\end{array}$ & $\begin{array}{l}\text { 4/7 ADP, } \\
\text { remoción } \\
\text { solo vía Corte } \\
\text { Apelaciones } \\
\end{array}$ & SI & NO \\
\hline \multirow[t]{3}{*}{ ENAP } & SI, estrecho & $\begin{array}{l}\text { Menor desde } \\
2017, \text { pero } \\
\text { control de } \\
\text { proyectos }\end{array}$ & $\begin{array}{l}\text { 4/7 ADP, pero } \\
\text { remoción } \\
\text { discrecional }\end{array}$ & SI & $\mathrm{NO}$ \\
\hline & \multicolumn{3}{|c|}{ DERECHO APLICABLE } & \multicolumn{2}{|c|}{ OTROS INDICIOS } \\
\hline & $\begin{array}{l}\text { Recursos } \\
\text { de derecho } \\
\text { público }\end{array}$ & \begin{tabular}{|c|} 
Sujeto a \\
Derecho de \\
Sociedades Libre \\
competencia \\
Laboral
\end{tabular} & $\begin{array}{l}\text { Aplica derecho } \\
\text { de quiebra }\end{array}$ & $\begin{array}{l}\text { Inmunidad } \\
\text { invocada }\end{array}$ & $\begin{array}{l}\text { Representación } \\
\text { judicial por } \\
\text { CDE }\end{array}$ \\
\hline CODELCO & \begin{tabular}{|l} 
SI, pero \\
solo amparo \\
económico
\end{tabular} & SI & NO & NO & NO \\
\hline ENAP & \begin{tabular}{|l} 
SI, pero \\
solo amparo \\
económico
\end{tabular} & SI & NO & NO & NO \\
\hline
\end{tabular}

\section{CONCLUSIONES}

Este artículo examinó si las acciones y omisiones de CODELCO y ENAP, particularmente, en materia ambiental y de derechos humanos, son directamente atribuibles al Estado de Chile. Mientras las definiciones sobre la materia parten de teorías bastante distintas dependiendo del órgano al que consultamos -el SIA tiende a una atribución en base al a mera propiedad, a pesar de un caso reciente que permitiría una lectura más diferenciada; el Proyecto y el TEDH atribuyen solo en base a la función gubernamental y el control sobre la empresa-, la respuesta a la pregunta es afirmativa bajo todas las teorías, incluso las más restrictivas o exigentes.

Estas atribuyen, principalmente, dependiendo de la composición, nombramiento y remoción de los directorios, la aprobación de los presupuestos y otras decisiones estratégicas o diarias por parte del ejecutivo, la sujeción a controles que solamente aplican a órganos públicos, y en general, la pregunta si el régimen jurídico aplicable es el mismo que rige las empresas privadas, tal como en materia de quiebra, derecho laboral o tributario.

${ }_{133}$ Elaboración con datos propios. A mayor oscuridad del color, mayor ponderación del criterio. Criterio decisivo en negrita. 
Revisando la normativa general que rige a las empresas públicas en Chile, además de las reglas específicas sobre ENAP y CODELCO, es especialmente la injerencia directa del poder ejecutivo -vía los ministerios de Hacienda, Minería, Energía y MIDESO- en la aprobación de los proyectos de las empresas la que nos lleva a concluir que los actos y las omisiones de las dos empresas en materia de derechos humanos serían atribuibles directamente al Estado de Chile. Constituye un control previo de las actividades empresariales y no solamente un control posterior como el que se realiza, a través de la regulación y fiscalización, a las empresas privadas.

Será objeto de otro artículo describir el alcance y contenido de estas obligaciones. Hay una fuerte hipótesis de que la exigencia es mayor si se comprueba un continuo flujo de información entre la EPE y los órganos del ejecutivo, tal como lo recomienda también el concepto del "propietario informado y activo" de las Directrices de la OCDE.

Ciertamente, la responsabilidad internacional directa de las EPE nunca exime de responsabilidad (internacional) a los órganos políticos, de fiscalización, y judiciales de un Estado, especialmente, a quienes tienen injerencia más directa en las decisiones sobre proyectos, la regulación en materia de empresas y $\mathrm{DDHH}$, y la fiscalización. Lo que este artículo mostró es que las dos empresas de propiedad del Estado de Chile más grandes, ENAP y CODELCO, pueden generar directamente responsabilidad internacional del Estado, particularmente, si violaran normas internacionales en materia de derechos humanos y ambientales.

\section{BIBLIOGRAFÍA CITADA}

Ahumada, Omar (2003): "Una nueva ley para el control ciudadano de la administración", Revista Enfoques, vol. 2, No 1: pp. 115-128.

Aróstica, Iván (2001): Derecho administrativo económico (Santiago, Universidad Santo Tomás).

BACKER, Larry Catá (2017): “The Human Rights Obligations of State-Owned Enterprises (SOEs): Emerging Conceptual Structures and Principles in National and International Law and Policy", Vanderbilt Journal of Transnational Law, vol. 50, № 4: pp. 827-888.

BADIA, Albert (2014): Piercing the Veil of State Enterprises in International Arbitration (Leiden, Kluwer Law International).

Barnes, Mihaela (2019): "International Investment Law and State-Owned Entities: Recurrent Key Issues and Future Directions", Yearbook on International Investment Law \& Policy (Oxford, Oxford University Press) pp. 432-456.

Bassa, Jaime y Viera, Christian (2012): "Un nuevo giro hermenéutico de la Corte Suprema en la aplicación del recurso de amparo", Revista de Derecho de la Pontificia Universidad Católica de Valparaiso, vol. 38 No 1: pp. 661-683.

BROWER, Jorge (2016): La responsabilidad de las empresas del estado en la afectación del medio ambiente, Tesis para optar al grado de Licenciado en la Facultad de Derecho de la Universidad Diego Portales.

Blyschak, Paul (2011): "State Owned Enterprises and International Investment Treaties", Journal of International Law and International Relations, vol. 6: pp. 1-35.

Cordero, Luis (2015): Lecciones de derecho administrativo (Santiago, LegalPublishing). 
Covarrubias, Ignacio (2004): "Subsidiariedad y Estado Empresario", Revista de Derecho Público, No 66, pp. 251-273.

Cortesi, Giulio (2017): "ICSID Jurisdiction with Regard to State-Owned Enterprises Moving Toward an Approach Based on General International Law", The Law and Practice of International Courts and Tribunals No 16, pp. 108-138.

Cuervo-Vazurra, Álvaro (2018): State-Owned Multinationals (Palgrave Macmillan).

Dereje, Jonas (2016): Staatsnahe Unternehmen. Die Zurechnungsproblematik im Internationalen Investitionsrecht und weiteren Bereichen des Völkerrechts (Baden-Baden, Nomos).

De Stefano, Carlo (2020): Attribution in International Law and Arbitration (Oxford, Oxford University Press).

Ding, Ru (2014): “Public Body' or Not: Chinese State-Owned Enterprise”, Journal of World Trade, vol. 48, No 1: pp. 167-190.

FEIT, Michael (2010): "Responsibility of the State under International Law for the Breach of Contract Committed by a State-Owned Entity", Berkeley Journal of International Law Vol. 28 No 1: pp. 142-177.

Feldman, Mark (2016): "State Owned Enterprises as Claimant in International Investment Arbitration”, ICSID Review, Vol. 31: pp. 27-28.

Fermandois, Arturo (2006): Derecho constitucional económico (Santiago, Universidad Católica).

GARRIDO, Raúl (1966): Las empresas estatales (Santiago, Editorial Jurídica).

Hernández, Domingo (2010): "El recurso de amparo económico: una tendencia jurisprudencial peligrosamente reduccionista", Revista de Estudios Constitucionales, Año 8, No 1: pp. 443-466.

Hervé, Dominique y Schönsteiner, Judith (2012): "Empresas, medio ambiente y derechos humanos: la zona industrial de Quintero-Puchuncavî", en Informe anual sobre derechos humanos en Chile 2012 (Santiago, Universidad Diego Portales) pp. 131-162.

Instituto Nacional de Derechos Humanos (2018): "Recursos naturales, empresas y derechos humanos. Análisis del impacto de actividades productivas sobre los recursos naturales y el medio ambiente", en Informe anual situación de los derechos humanos en Chile 2018 (Santiago, Instituto Nacional de Derechos Humanos).

JARA, Jaime (2008): "La garantía jurídica de la unidad del procedimiento administrativo en la Ley No 19.880”, Revista de Derecho Público, vol. 70: p. 293.

Latorre, Patricio (2008): "Las sociedades estatales en el ordenamiento jurídico chileno: naturaleza, límites y control de sus actividades", Revista de Derecho de la Pontificia Universidad Católica de Valparaíso, No XXX: pp. 223-240.

LeE, Jaemin (2015): "State Responsibility and Government Affiliated Entities in International Economic Law”, Journal of World Trade, vol. 49, No 1: pp. 117-151.

LeE, Jaemin (2019): “Trade Agreements' New Frontier - Regulation of State-Owned Enterprises and Outstanding Systemic Challenges", Asian Journal of WTO and International Health Law and Policy, vol. 14, No 1: pp. 33-72.

Loebenstein, Beatriz von (2018): Empresas públicas. Sus caracteristicas, naturaleza jurídica, marco normativo, régimen jurídico y su vinculación con la administración del Estado (Santiago, Editorial Hammurabi). 
López, Sebastián (2006): Garantía constitucional de la no discriminación económica (Santiago, Editorial Jurídica).

Medina, Cecilia (2018): La Convención Americana de Derechos Humanos (Ediciones UDP).

MA, Xili (2019): "Advancing Direct Corporate Accountability in International Human Rights Law: The Role of State-Owned Enterprises"”, Frontiers of Law in China, vol. 14, No 2: pp. 231-273.

NAVARRO, Enrique (1995): "El recurso de amparo económico en la jurisprudencia (19901995)", Revista de Derecho Público, No 57/58: pp. 263-275.

Navarro, Enrique (2000): "El Estado Empresario a la luz de la Constitución de 1980", Revista de Derecho Público, vol. 62: pp. 32-47.

Nogueira, Humberto (2010): "Análisis crítico sobre línea jurisprudencial de la sala constitucional de la Excma. Corte Suprema de Justicia sobre el recurso de amparo económico", Ius et Praxis, Año 16, No 2: pp. 415-442.

Pardow, Diego y Torres, Pablo (2016): "Empresas del Estado y la relevancia del gobierno corporativo análisis a propósito de la ampliación del giro de ENAP”, en UNIVERSIDAD Diego Portales, Anuario de Derecho Público, No 1, 2016: pp. 316-333.

Pardow, Diego y Vallejo, Rodrigo (2008): "Derribando Mito Estado Empresario", Revista Chilena de Derecho, vol. 35 No 1: pp. 135-156.

PARrA, Alejandra (2017): "La propiedad y la administración de la Corporación Nacional del Cobre de Chile en razón de las innovaciones introducidas desde la vigencia de la Ley No 20.392 de 2009”, Universidad de Chile, Memoria para optar al grado de licenciada en Ciencias Jurídicas y Sociales, profesor guía: Max Spiess.

Petrochilos, Georgios (2015): "Attribution of Conduct of Non-State Organ Entities: An Introduction", en: Lalani, Shaheeza y Polanco, Rodrigo (eds.) The Role of the State in Investor State Arbitration (Leiden, Brill/Martinus Nijhoff Publishers) pp. 351-360.

Pisillo Mazzeschi, Riccardo (2008): Responsabilité De L'etat Pour Violation Des Obligations Positives Relatives Aux Droits De L'homme (Volume 333), Collected Courses of The Hague Academy of International LaW

Ponce de León, Sandra (2014): "La acción de amparo económico", en Silva, María Pía y Henríquez, Miriam (coords.): Acciones protectoras de derechos fundamentales (Santiago, Legal Publishing) pp. 97-126.

Rajavuori, Mikko (2015): "How Should States Own? Heinisch v Germany and the Emergence of Human Rights Sensitive State Ownership", The European Journal of International Law, vol. 26, No 3: pp. 727-746.

SCHÖNSTEINER, Judith (2019): "Attribution of state responsibility for actions or omissions of State-owned enterprises in human rights matters", University of Pennsylvania Journal of International Law, vol. 40, No 4: pp. 895-936.

Silva Bascuñán, Alejandro (1997): Tratado de Derecho Constitucional (Santiago, Editorial Jurídica).

Soto Kloss, Eduardo (1999): "La Actividad Económica en la Constitución Política de la República de Chile”, Revista Ius Publicum, No 2: pp. 119-129. 
Soto Kloss, Eduardo (2000): "Legitimidad de la distribución gratuita por un tercero de un periódico en la red de transporte de Metro S.A.", Revista Chilena de Derecho, vol. 27 No 2: pp. 251-265.

Vanneste, Frederic (2006): General International Law Before Human Rights Courts (Intersentia).

Wu, Yingying (2020): Reforming WTO Rules on State-Owned Enterprises (Singapore, Springer Verlag).

\section{Normativa Citada}

Ley No 10.336 (29/3/1952) Ley de organización y atribuciones de la Contraloría General de la República.

LEY No 13.196 (1/1/1958) Reservada del cobre.

Decreto Ley No $824(31 / 12 / 1974)$ Ley sobre impuesto a la renta.

Decreto Ley No 1.056 (7/6/1975) Normas complementarias relativas a la reducción del gasto público y al mejor ordenamiento y control de personal.

DeCReto Ley No 1.263 (28/11/1975) Decreto Ley Orgánico de administración financiera del Estado.

Decreto Ley No 1.350 (10/10/1976) Crea la Corporación Nacional del Cobre de Chile.

Decreto Ley No 2.398 (1/12/1978) Normas complementarias de administración financiera y de incidencia presupuestaria.

LEY No 18.196 (29/12/1982) Normas complementarias de administración financiera, personal y de incidencia presupuestaria.

LEY No 18.482 (28/12/1985) Normas complementarias de administración financiera y de incidencia presupuestaria.

LEY No 18.575 (5/12/1986) Orgánica constitucional de bases de la administración del Estado.

LEY No 18.918 (5/2/1990) Ley orgánica constitucional del Congreso Nacional.

LEY No 19.628 (28/8/1999) Sobre protección de la vida privada.

Decreto con Fuerza de Ley No 1 del Ministerio de Minería (24/4/1987) Fija texto refundido, coordinado y sistematizado de la Ley No 9.618, que crea la Empresa Nacional del Petróleo.

LEY No 20.285 (20/8/2008) Sobre acceso a la información pública.

LEY No 21.174 (26/9/2019) Establece nuevo mecanismo de financiamiento de las capacidades estratégicas de la defensa nacional.

LEY No 20.977 (22/12/2016) Exige la publicación en el Diario Oficial de la Ley No 13.196, Reservada del cobre.

Historia DE LA LEY No 21.025 (7/8/2017): Establece un nuevo gobierno corporativo de la Empresa Nacional del Petróleo.

Decreto con Fuerza de Ley No 1 del Ministerio de Hacienda (22/11/2016) Fija el texto refundido, coordinado y sistematizado de la Ley Orgánica del Consejo de Defensa del Estado.

Decreto No 2.421 del Ministerio de Hacienda (7/7/1964) Fija texto refundido, coordinado y sistematizado de la Ley No 10.336 Ley Orgánica Constitucional de la Contraloría General de la República. 


\section{JURISPRUDENCIA CITADA}

NACIONAL

Alcayaga con Fisco y CODElCO (2000): 10 Juzgado Civil de Santiago, Rol 32452000.

Asimet A.G. con Corporación Nacional del Cobre (1993): Corte Suprema, 25 de mayo de 1993 (Amparo Económico) en MicroJuris, código de búsqueda MJJ2363 Fecha de consulta 21 de enero de 2019.

Asociación Nacional de la Prensa A.G. con Empresa de Transporte de Pasajeros MeTRO S.A. (2000): Corte Suprema, 31 de enero de 2000 (Amparo económico) en MicroJuris, código de búsqueda MJJ332, Fecha de consulta 21 de enero de 2019.

Bautista con Fisco (2011): 6o Juzgado Civil de Santiago, Rol C-47314-2011.

Bozinovic y otro con Empresa Nacional de Petróleos y otro (2012): $25^{\circ}$ Juzgado Civil de Santiago, Rol C-20669-2012.

Chilexpress S.A. y Línea Aérea Nacional S.A. con Empresa de Correos de Chile (1999): Corte Suprema, 17 marzo de 1999 (Amparo económico), en MicroJuris, código de búsqueda MJJ1056, Fecha de consulta 21 de enero de 2019.

Claussen Calvo con Fisco de Chile y CODElCO Chile División Chuquicamata (2018): $1^{\circ}$ Juzgado de Letras en lo Civil de Antofagasta, Rol C-720-2018.

Corporación Nacional del Cobre con Inversiones Angloamerican Sur S.A. y otros (2011): Corte de Apelaciones de Santiago, Rol 21879-2011.

Farías Zapata con Empresa Portuaria de Iquique (2003): Corte de Apelaciones de Iquique Rol 93-2003. 15 de diciembre de 2009 (Despido injustificado - Recurso de nulidad), en MicroJuris, código de búsqueda MJJ22307, Fecha de consulta 21 de enero de 2019.

Fonseca con Corporación Nacional del Cobre y Fisco (2001): 15º Juzgado Civil de Santiago, Rol 3968-2001.

InComin S.A. con Enami (2000): Corte de Apelaciones de Santiago, 10 de octubre de 2000 2000 (Recurso de Protección), en MicroJuris, código de búsqueda MJJ3623, Fecha de consulta 21 de enero de 2019.

Mardones Cepeda con Banco del Estado (2008): Corte Suprema, 29 de julio de 2008 (Indemnización de perjuicios - Recurso de casación en el fondo) MJJ17940, en MicroJuris, código de búsqueda MJJ17940, Fecha de consulta 21 de enero de 2019.

Portuaria Anden San Antonio con Empresa Portuaria San Antonio (2009): CS Rol 6511-2009.

Quinzacara Toro con ENAP y Fisco (2012): 3o juzgado de Letras de Punta Arenas, Rol 1043-2012.

Sociedad Visal Ltda. con Empresa Portuaria de Arica (2007): Corte Suprema Rol 14282007.

Socolibros Ltda. con Editorial Jurídica de Chile. (1997): Corte de Apelaciones de Santiago, 17 de marzo de 1997 (Amparo económico), en MicroJuris, código de búsqueda MJJ73, Fecha de consulta 21 de enero de 2019.

TORres con ENAP (2004): 1o Juzgado Civil de Santiago 9796-2004. 


\section{DICTÁMENES Y OTRAS RESOLUCIONES}

Dictamen de la Contraloría General de la República (1994): No 16.164, de 16 de agosto de 1994.

Dictamen de la Contraloría General de la República (2015): No 23.608 del 23 de marzo de 2015.

Dictamen de la Contraloría General de la República (2016): No 83.133, de 16 de noviembre de 2016.

Dictamen de la Contraloría General de la República (2017): No 18.850, de 24 de mayo de 2017.

Dictamen de la Contraloría General de la República (2017): No 15.759, de 02 de mayo de 2017.

Dictamen de la Contraloría General de la República (2017): No 18.589, de 23 de mayo de 2017.

Dictamen de la Contraloría General de la República (2017) No 45.162 del 29 de diciembre de 2017.

Dictamen de la Contraloría General de la República (2018): No 13.564, de 25 de mayo de 2018.

Dictamen de la Contraloría General de la República (2018): No 16.449, de 29 de junio de 2018.

Contraloría General de la República, Resolución (2008): Resolución No 1.600 Fija normas sobre exención del trámite de toma de razón.

Ministerio de Hacienda (1978): sobre Normas Complementarias de Administración Financiera y de Incidencia Presupuestaria.

Servicio de Impuestos Internos (2018): “Ordinario No 470 Renta -actual ley sobre impuesto a la -art. 14, letras a) y b) y No 3, art. 56, No 3, art. 63 -decreto ley No 2.398, de 1978, art. 2 -circular No 49, de 2016", disponible en: http://www.sii.cl/normativa_ legislacion/jurisprudencia_administrativa/ley_impuesto_renta/2018/ja470.htm. Fecha de consulta: 20 de enero de 2019.

\section{INTERNACIONAL}

CORTE INTERNACIONAL DE JUSTICIA

CERTAin IRANian Assets (Republic of IRAN vs. Estados Unidos de América), Corte Internacional de Justicia, Excepciones preliminares, I.C.J. Reports 2019, p. 7.

\section{CORTE IDH}

Abrill Alosilla vs. Perú. Corte Interamericana de Derechos Humanos. Sentencia del 4 de marzo de 2011. Serie C No 233.

Cantos vs. Argentina. Corte Interamericana de Derechos Humanos. Sentencia del 28 de noviembre de 2002. Serie C No 97.

Pueblo indígena Kichina de SaRayaku vs. ECUador. Corte Interamericana de Derechos Humanos. Sentencia del 27 de junio de 2012. Serie C No 245. 
Medioambiente y Derechos Humanos, Opinión Consultiva solicitada por la República de Colombia, Corte Interamericana de Derechos Humanos. Opinión del 15 de noviembre de 2017. Serie A OC-23/17.

Muelle Flores VS. Perú. Corte Interamericana de Derechos Humanos. Sentencia del 6 de marzo de 2019. Serie C No 375.

Trabajadores Cesados de Petroperú y otros vs. Perú. Corte Interamericana de Derechos Humanos. Sentencia del 23 de noviembre de 2017. Serie C No 344.

Tribunal Europeo de Derechos Humanos

BURMYCH Vs. UCRANIA (2017): Tribunal Europeo de Derechos Humanos, sentencia del 12 de octubre de 2017, App. 46852/13 y otras.

Cosmos Maritime Trading and Shipping Agency vs. UCRania (2019). Tribunal Europeo de Derechos Humanos, sentencia del 27 de junio de 2019, App. 53427/09.

Dimitar Yordanov vs. Bulgaria (2018): Tribunal Europeo de Derechos Humanos, sentencia del 6 de septiembre de 2018, App. 3401/09.

Heinisch vs. Alemania (2011): Tribunal Europeo de Derechos Humanos, sentencia del 21 de julio de 2011. App. 28274/08

IsLamic Republic of IRAN SHIPPING vs. TuRquía (2007): Tribunal Europeo de Derechos Humanos, sentencia del 13 de diciembre de 2013, App. 40998/98.

JKP Vodovod Kraljevo vs. Serbia (2018): Tribunal Europeo de Derechos Humanos, decisión sobre inadmisibilidad del 16 de octubre de 2019, Apps. 57691/09 y 19719/10.

KhadiJa Ismayilova vs. AzerbaiyAn (2019): Tribunal Europeo de Derechos Humanos, sentencia del 20 de enero de 2019, App. 65286/13 y 57270/14

KRNDIJA Vs. SERBIA (2017): Tribunal Europeo de Derechos Humanos, sentencia del 27 de junio de 2017, App. 30723/09 y tres otras.

KuRŞUN vs. TuRQUía (2018): Tribunal Europeo de Derechos Humanos, sentencia del 30 de octubre de 2018, App. 22677/10.

LangNer VS. Alemania (2015): Tribunal Europeo de Derechos Humanos, sentencia del 17 de septiembre de 2015, App. No. 14464/11.

MYKHAYLENKY VS. UCRANIA (2004): Tribunal Europeo de Derechos Humanos, sentencia del 30 de mayo de 2013, App. 49069/11.

RADio FRANCE Y otros Vs. FRANCIA (2003): TEDH, decisión sobre admisibilidad del 23 de septiembre de 2003, App. 53984/00.

ŠIMAITIENÉ Vs. LITUANIA (2017): Tribunal Europeo de Derechos Humanos, sentencia del 21 de mayo de 2017, App. 55056/10.

State Holding Company Luganskvugillya vs. Ukraine (2009): Tribunal Europeo de Derechos Humanos, decisión sobre inadmisibilidad del 27 de enero de 2009, App. 23938/05.

Transpetrol vs. Eslovaquia (2011): Tribunal Europeo de Derechos Humanos, sentencia del 15 de noviembre de 2011, App. 28502/08.

VORONKOV Vs. RUSIA (2015): Tribunal Europeo de Derechos Humanos, sentencia del 30 de julio de 2015, App 39678/03. 
Revista Chilena de Derecho, vol. 47 No 3, pp. 757 - 783 [2020]

Schönsteiner, Judith / Martínez, Vicente / Miranda, Carlos — "Atribuibilidad al Estado de Chile de actos y omisiones ..."

YeRSHOVA Vs. RUSIA (2010): Tribunal Europeo de Derechos Humanos, sentencia del 8 de abril de 2010, App. 1387/04.

Zastava IT TURS VS. SERBIA (2013): Tribunal Europeo de Derechos Humanos, decisión sobre inadmisibilidad del 9 de abril de 2013, App. 24922/12.

\section{RESOLUCIONES DE ORGANISMOS INTERNACIONALES}

Comisión de Derecho Internacional de Naciones Unidas: "Proyecto de Artículos sobre Responsabilidad del Estado por hechos internacionalmente ilícitos, con Comentarios", A/56/10, en Naciones Unidas, Anuario de la Comisión de Derecho Internacional, A/ CN.4/SER.A/2001/Add.1 (Nueva York y Ginebra, 2007).

Comisión Interamericana de Derechos Humanos: Empresas y Derechos Humanos. Estándares Interamericanos, OEA/Ser.L/V/II CIDH/REDESCA/INF.1/19 (1 de noviembre de 2019).

Naciones Unidas, Comité de Derechos Económicos, Sociales y Culturales: Observación General No 24 sobre las obligaciones de los Estados en virtud del Pacto Internacional de Derechos Económicos, Sociales y Culturales en el contexto de las actividades empresariales, E/C.12/GC/24 (10 de agosto de 2017).

Naciones Unidas, Consejo de Derechos Humanos: Principios Rectores sobre Empresas y Derechos Humanos, A/HRC/RES/17/4 (6 de julio de 2011).

OCDE (2015): Directrices de la OCDE sobre el Gobierno Corporativo de las Empresas Públicas, Edición 2015 (París, Éditions OCDE).

\section{SOLICITUDES DE ACCESO A LA INFORMACIÓN}

SAI No AX001T0000695 al Consejo de Defensa del Estado, presentada el 2 de enero de 2019, respondida por resolución No 275, de fecha 18 de enero de 2019.

\section{OTROS}

CODELCO (2018): Estados Financieros Consolidados de CODELCO al 31 de diciembre de 2017 (Santiago).

ENAP (2018): Memoria Anual 2017 (Santiago).

CODELCO (2008): NCC 24 sobre Análisis de Riesgos en Materiales de Sustentabilidad para inversiones de Capital de la Corporación, Revisión No 2. 
